\title{
Soft tissue microcirculation around the healthy Achilles tendon: a cross-sectional study focusing on the Achilles tendon and dorsal surgical approaches to the hindfoot
}

Kajetan Klos ${ }^{1}$, Boyko Gueorguiev², John Bennet Carow ${ }^{3}$, Ali Modabber ${ }^{4}$, Sven Nebelung ${ }^{5}$, Bong-Sung Kim ${ }^{6}$ Klemens Horst ${ }^{3}$, Christian David Weber ${ }^{3}$ and Matthias Knobe ${ }^{3^{*}}$ (D)

\begin{abstract}
Background: Dorsal approaches to the hindfoot are frequently used. Furthermore, the vascular supply is discussed as a possible cause for ruptures and degeneration of the Achilles tendon. The aim of this study was to evaluate the microperfusion of three possible posterior approaches to the hindfoot and different areas of the Achilles tendon.

Methods: In 111 subjects, a laser Doppler/white light spectroscopy was used to measure microperfusion in terms of blood flow (Flow) and capillary venous oxygen saturation (SO2) in the hindfoot and Achilles tendon.

Measurements were performed at two measurement points (MP, proximal and distal) of three dorsal approaches (medial, lateral and central) and inside the Achilles tendon.

Results: Microperfusion differed partially between the surgical approaches. The medial and the lateral approaches were significantly superior to the central approach with regard to Flow in both MP $(p<0.001)$, while SO2 was significantly higher at the proximal measurement point (MP 1; $p<0.001)$. In this area, the lateral approach was significantly superior to the medial approach regarding Flow (MP $1 ; p=0.012$ ).

The Achilles tendon exhibited a significantly reduced microperfusion $5 \mathrm{~cm}$ proximal to the calcaneal tubercle (SO2 $p=0.001$; Flow $p=0.048$ ). Demographic factors, such as body mass index and age, had different effects.

Microcirculation was partially superior in men and negatively affected by smoking.

Conclusions: Soft tissue microcirculation on the lateral and medial side of the healthy Achilles tendon was better than centrally on the tendon. Proximally, the lateral approach was better than the medial approach. These circumstances could provide advantages regarding the surgical approach. The Achilles tendon exhibited significantly reduced microperfusion at the typical side of degeneration and rupture. This circumstance could be a possible cause of degenerative processes.
\end{abstract}

Keywords: Achilles tendon, Doppler/white light spectroscopy, Hindfoot surgical approach, Humans, Microcirculation

\footnotetext{
* Correspondence: mknobe@ukaachen.de

${ }^{3}$ Department of Orthopaedic Trauma, University of Aachen Medical Center,

Aachen, Germany

Full list of author information is available at the end of the article
}

(c) The Author(s). 2018 Open Access This article is distributed under the terms of the Creative Commons Attribution 4.0 International License (http://creativecommons.org/licenses/by/4.0/), which permits unrestricted use, distribution, and reproduction in any medium, provided you give appropriate credit to the original author(s) and the source, provide a link to the Creative Commons license, and indicate if changes were made. The Creative Commons Public Domain Dedication waiver (http://creativecommons.org/publicdomain/zero/1.0/) applies to the data made available in this article, unless otherwise stated. 


\section{Background}

Dorsal surgical approaches to the hindfoot are frequently used for a variety of reasons, such as the treatment of Achilles tendon ruptures, tendinopathies, and Haglund's deformity [1-8]. Achilles tendon lengthening may also be necessary in the context of pes planovalgus [9] corrections and for treatment of Charcot arthropathies [10] or other deformities [11]. Furthermore, hindfoot arthrodesis and osteosynthesis can be treated via a dorsal approach [12]. However, wound healing problems are not uncommon in this region. In a report by Paavola et al. [2], a series of patients were operated because of the presence of chronic Achilles tendon degeneration. Of these 423 patients, 14 developed skin necrosis and 11 developed superficial infections. This data is confirmed by other studies [1].

Three surgical approaches to the dorsal hindfoot are generally used: central, medial, or lateral to the Achilles tendon [3-5]. The lateral approach provides good visualization of the posterior distal upper and lower ankle and is therefore well suited for hindfoot arthrodesis and fracture repair [6-8]. However, due to the proximity of the sural nerve, there is a risk of nerve injury accompanied with this approach. The central approach to the Achilles tendon is particularly suitable for treatment of ruptures and tendinopathies $[1,13]$. According to Hammit et al. [14], a central approach with subsequent longitudinal incision straight through the Achilles tendon provides excellent visualization of the distal tibia, ankle, and hindfoot and can also be used for osteosyntheses, arthrodeses, and osteotomies. The main disadvantage of the central approach, however, is the possible resulting inflammation or painful scarring [14]. A medial approach is favored by many surgeons as it avoids scarring on the tendon and injury to the sural nerve $[3,5,15]$. Ruptures and degenerations typically occur in the middle of the tendon, and the vascular supply may be a contributing factor [16]. The interdependence between the vascular supply and tendon pathologies, however, is controversially discussed, since different studies have come to opposing conclusions $[17,18]$.

In the current study, comparison was made for soft tissue microperfusion of the healthy hindfoot at different areas of the Achilles tendon between the three posterior surgical approaches to draw conclusions about the wound healing potential and to evaluate microperfusion in the tendon itself. In addition, the effects of various demographic factors, such as body mass index (BMI), smoking, gender, and age, were evaluated.

\section{Methods}

A noninvasive measurement of the microperfusion of the hindfoot and Achilles tendon was performed in 111 volunteer participants with the use of an $\mathrm{O} 2 \mathrm{C}$ device (oxygen to see, laser Doppler/white light spectroscopy, LEA Medical Technology, Gießen, Germany). Out of the 111 subjects, 65 were men and 24 were smokers. Further characteristics are provided in Table 1. All participants provided written informed consent to participate in the study and have their data published. Exclusion criteria were peripheral arteriovenous obstructive disease, insulin-dependent diabetes mellitus, macroangiopathy, and previous surgeries or injury in the measurement area.

Measurements were carried out with each subject in a resting prone position. Firstly, a 2-mm-depth (superficial) flat probe was used to define six measuring points. The measurements were obtained for each subject at medial, lateral, and central (on the tendon) sites at $5 \mathrm{~cm}$ (measuring height $\mathrm{MH} 1$ ) and at $1 \mathrm{~cm}$ (measuring height $\mathrm{MH} 2$ ) proximal to the calcaneal tubercle (Fig. 1). The following two hemodynamic parameters were measured: blood flow (Flow, in arbitrary units [AU]) and capillary venous oxygen saturation (SO2 in \%) in vessels up to $100 \mu \mathrm{m}$ in diameter. Secondly, the microperfusion in the tendon (central) was measured with a second 8-mm-depth (in-depth) flat probe at the same locations MH1 $(5 \mathrm{~cm})$ and MH2 $(1 \mathrm{~cm})$. The parameters were compared among all subjects, as well as within several subgroups (men, women, smokers, nonsmokers).

\section{Statistics}

Statistical analysis was performed using SPSS 21 software (IBM, Armonk, NY, USA). Descriptive data are presented as mean values \pm standard error of the mean/ standard deviation and range. As the Shapiro-Wilk test indicated abnormally distributed values, nonparametric tests (Spearman rank, Mann-Whitney U test, Kruskal-Wallis test) were applied. $p$ value $<0.05$ was considered statistically significant with a $95 \%$ confidence interval.

\section{Results}

Significant correlations between the measured parameters and evaluated demographic factors, as well as significant differences between the measurement points, are visualized in Figs. 2 and 3.

Table 1 Subject characteristics

\begin{tabular}{llll}
\hline Characteristic & Mean & SD & Range \\
\hline Age (years) & 28.9 & 10.2 & $18.9-66.7$ \\
BMI $\left(\mathrm{kg} / \mathrm{m}^{2}\right)$ & 22.3 & 2.5 & $17.9-30$ \\
Systolic blood pressure $(\mathrm{mmHg})$ & 111 & 37 & $103-145$ \\
Diastolic blood pressure $(\mathrm{mmHg})$ & 79 & 5 & $67-90$ \\
\hline
\end{tabular}

$B M I$ body mass index 


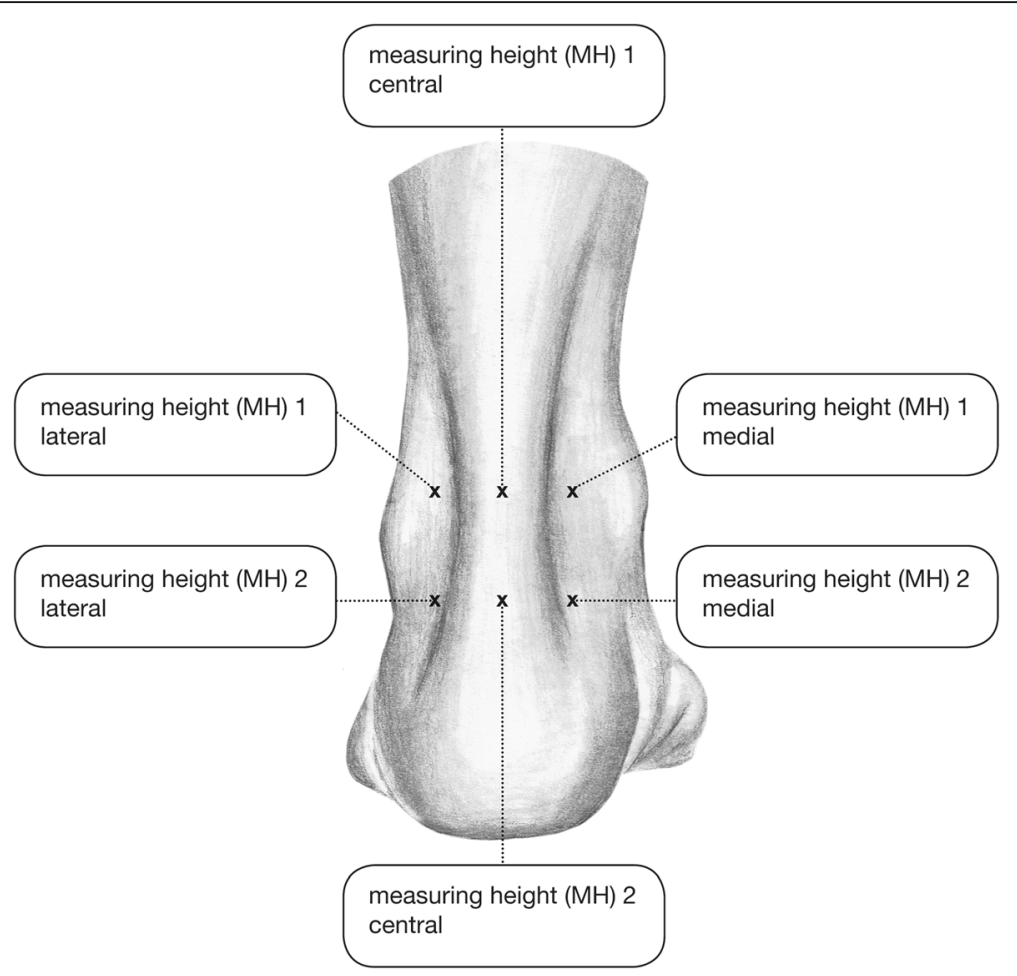

Fig. 1 The six different measurement points. At the central points, the microperfusion was measured in 2- and 8-mm depth, whereas at the lateral and medial points it was measured in 2-mm depth only

\section{Comparison of dermal microperfusion centrally against lateral and medial \\ Measuring height $\mathrm{MH} 1$}

Dermal microperfusion (SO2 and Flow) at measuring height 1 ( $\mathrm{MH} 1,5 \mathrm{~cm}$ proximal to the calcaneal tubercle) was lower at the central superficial site (on the tendon) than at the lateral and medial superficial sites (Table 2). The differences in SO2 and Flow were significant for the entire patient population and in the men and nonsmoker subgroups. For women, there was no significant difference in SO2 between lateral and central sites $(p=0.188)$, whereas for smokers no significant differences were found in Flow between lateral and central sites $(p=$ 0.144 ) as well as in SO2 for the central versus both lateral and medial sites $(p=0.092 ; p=0.280)$ (Table 2).

\section{Measuring height $\mathrm{MH} 2$}

At measuring height $2(\mathrm{MH} 2,1 \mathrm{~cm}$ proximal to the calcaneal tubercle), the Flow was significantly higher at the lateral and medial superficial sites than at the central superficial site (on the tendon) among all subjects, and also for men and nonsmokers (Table 3). In women and smokers, a significant difference was detected in Flow only between the lateral and central superficial sites $(p=0.012)$. $\mathrm{SO} 2$ did not differ significantly among the three sites.

\section{Dermal microperfusion at the lateral site compared with the medial site Measuring height $\mathrm{MH} 1$}

Comparison between the lateral and medial superficial sites of the tendon at $\mathrm{MH} 1$ revealed that microperfusion (Flow) was greater at the lateral site than at the medial site in the total subject population (mean Flow 15.7 AU vs. 13.1 AU; $p=0.012$ ) (Table 2). In the subgroups, the difference in Flow remained significant for men $(p=0.008)$ and nonsmokers $(p<0.001)$, but not in women $(p=0.349)$ and smokers $(p=0.4)$. There were no differences regarding oxygen saturation.

\section{Measuring height $\mathrm{MH} 2$}

Comparisons in Flow and SO2 between lateral and medial sites at MH2 yielded no significant differences for the subjects (Table 3 ).

\section{Microperfusion in the Achilles tendon}

Measurements in the tendon (central in 8-mm depth) showed significantly lower values for $\mathrm{MH} 1$ versus $\mathrm{MH} 2$ within all subjects for SO2 $(p=0.001)$ and Flow $(p=0.048)$ (Tables 2, 3, and 4). In the subgroups, those differences remained significant for SO2, but not for Flow (Tables 2, 3 , and 4). 


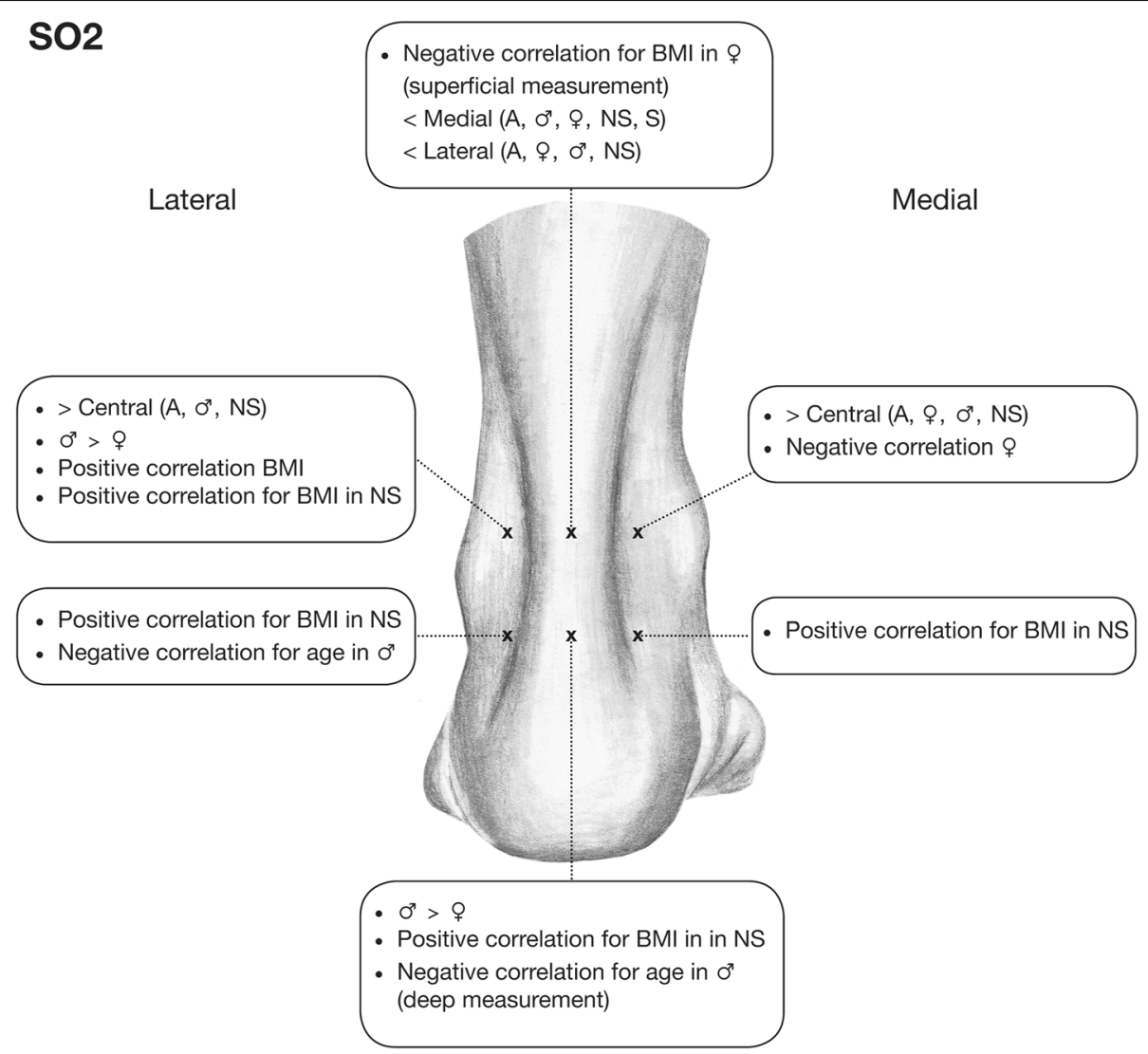

Fig. 2 Significant correlations between $\mathrm{SO} 2$ and the evaluated demographic factors as well as significant differences with regard to $\mathrm{SO} 2$ between all measurement points are illustrated for each measurement point. (A: all; NS: nonsmokers; S: smokers)

\section{Effect of BMI}

Within all subjects, BMI correlated significantly and positively with lateral (superficial) SO2 at MH1 $(p=0.011)$ and with medial (superficial) Flow at MH2 $(p=0.010)$ (Figs. 2 and 3).

\section{Effect of age}

Some isolated significant negative correlations with age were detected at $\mathrm{MH} 2$ for men regarding $\mathrm{SO} 2$ in the tendon (in-depth central, $p=0.037$ ) and for lateral (superficial) SO2 ( $p=0.038)$ (Fig. 2).

\section{Effect of gender}

Comparison between the genders among all subjects revealed significantly higher values for men at MH1 for $\mathrm{SO} 2(p=0.013)$ and Flow at the lateral site $(p=0.041)$, as well as at MH2 for SO2 in the tendon (in-depth; $p=0.002$ ) and for medial Flow ( $p=0.001$, Figs. 2 and 3$)$.

\section{Effect of smoking}

Comparison between nonsmokers and smokers among all subjects revealed a significantly better microperfusion for nonsmokers versus smokers in terms of Flow at MH1 lateral (superficially, $p=0.014$ ) and at MH2 medial (superficially, $p=0.043$ ) (Fig. 3).

\section{Discussion}

The $\mathrm{O} 2 \mathrm{C}$ device as a tool for noninvasive detection of hemoglobin saturation and blood flow using laser Doppler technique and white light spectroscopy allows for valid and reproducible quantitative determination of microcirculatory parameters [19-24], as well as identification of possible influencing factors in healthy subjects [23, 25]. Currently, O2C studies have provided evidence for altered soft tissue microcirculation after peripheral artery occlusive disease [26] as well as for individual healing tendencies depending on the microcirculatory parameters in patients with burns [27, 28] and chronic diabetic foot ulcers [19]. In this context, recent data in the treatment of fractures of the thoracolumbar spine indicated differences in microcirculation between open and minimally invasive approaches [24]. High oxygen saturation and high blood flow values clearly contribute to a good prognosis of wound healing. To the best of our knowledge, there are no existing studies investigating microcirculation as a 


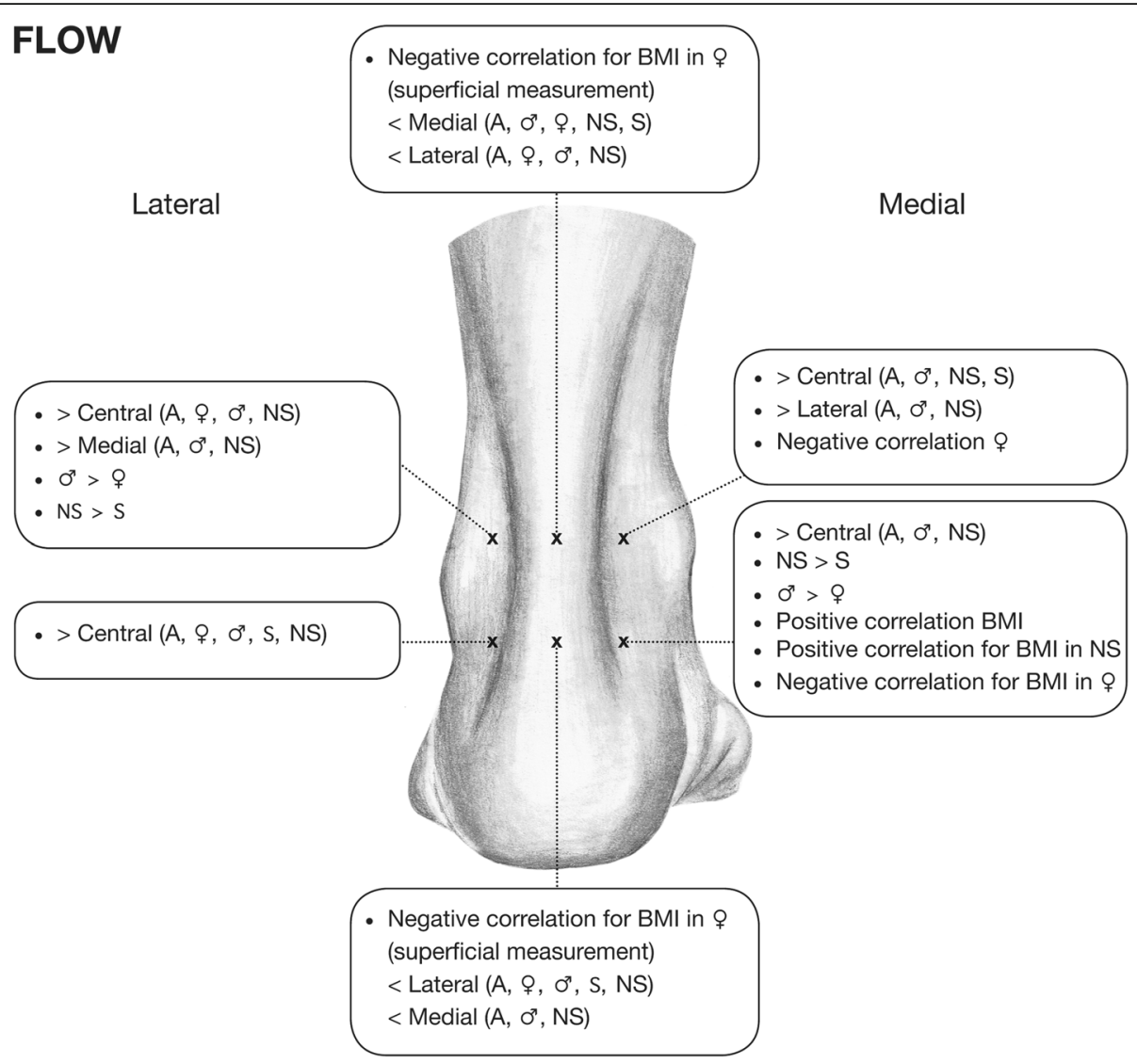

Fig. 3 Significant correlations between Flow and the evaluated demographic factors and significant differences with regard to the Flow between all different measurement points are illustrated for each measurement point

parameter for evaluation of possible surgical approaches at the dorsal hindfoot.

The lateral approach is supplied by the peroneal artery. This approach exhibited the best microcirculation in the current study with a significant difference compared to the central approach for Flow, partly for $\mathrm{SO} 2$, and compared to the medial approach to some extent for Flow. Surgical access to the Achilles tendon through this site is considered as a critical intervention because of its proximity to the sural nerve [29], even though it

Table 2 Data for measurement height $M H 1$

\begin{tabular}{|c|c|c|c|c|c|c|c|c|}
\hline \multirow[t]{2}{*}{ Groups } & \multirow[t]{2}{*}{ Variable } & \multicolumn{4}{|c|}{ Mean \pm SEM } & \multicolumn{3}{|l|}{$p$ value } \\
\hline & & $\mathrm{CS}$ & $\mathrm{cd}$ & Is & $\mathrm{ms}$ & CS vs. Is & cs vs. ms & Is vs. ms \\
\hline \multirow[t]{2}{*}{ All } & $\mathrm{SO} 2$ & $23.5 \pm 1.6$ & $54.9 \pm 2.3$ & $38.1 \pm 1.8$ & $36.8 \pm 1.9$ & $<0.001$ & $<0.001$ & 0.751 \\
\hline & Flow & $7.4 \pm 0.6$ & $72.4 \pm 2.8$ & $15.7 \pm 0.9$ & $13.1 \pm 0.9$ & $<0.001$ & $<0.001$ & 0.012 \\
\hline \multirow[t]{2}{*}{ Men } & $\mathrm{SO} 2$ & $23.3 \pm 2.2$ & $57.0 \pm 3.0$ & $41.9 \pm 2.2$ & $38.7 \pm 2.5$ & $<0.001$ & $<0.001$ & 0.371 \\
\hline & Flow & $7.4 \pm 0.8$ & $77.0 \pm 4.4$ & $17.0 \pm 1.1$ & $13.1 \pm 0.9$ & $<0.001$ & $<0.001$ & 0.008 \\
\hline \multirow[t]{2}{*}{ Women } & $\mathrm{SO} 2$ & $23.8 \pm 2.5$ & $51.8 \pm 3.6$ & $32.5 \pm 3.0$ & $34.0 \pm 3.0$ & 0.188 & 0.036 & 0.620 \\
\hline & Flow & $7.4 \pm 0.7$ & $65.8 \pm 2.4$ & $13.6 \pm 1.3$ & $13.2 \pm 1.9$ & $<0.001$ & 0.004 & 0.349 \\
\hline \multirow[t]{2}{*}{ Nonsmokers } & $\mathrm{SO} 2$ & $23.6 \pm 1.8$ & $53.6 \pm 2.7$ & $38.5 \pm 2.0$ & $37.3 \pm 2.2$ & $<0.001$ & $<0.001$ & 0.830 \\
\hline & Flow & $7.5 \pm 0.7$ & $73.0 \pm 3.1$ & $16.6 \pm 1.0$ & $12.9 \pm 1.1$ & $<0.001$ & $<0.001$ & $<0.001$ \\
\hline \multirow[t]{2}{*}{ Smokers } & $\mathrm{SO} 2$ & $23.0 \pm 3.9$ & $59.3 \pm 4.1$ & $36.7 \pm 4.4$ & $34.9 \pm 4.3$ & 0.092 & 0.280 & 0.641 \\
\hline & Flow & $7.1 \pm 1.0$ & $70.1 \pm 6.3$ & $12.1 \pm 1.6$ & $14.1 \pm 1.8$ & 0.144 & 0.004 & 0.400 \\
\hline
\end{tabular}

$\mathrm{SO} 2$ in \%, Flow in $\mathrm{AU}$

cs central superficial ( $2 \mathrm{~mm}$ deep), $c d$ central in-depth ( $8 \mathrm{~mm}$ deep), Is lateral superficial ( $2 \mathrm{~mm}$ deep), $m s$ superficial ( $2 \mathrm{~mm}$ deep), SEM standard error of the mean 
Table 3 Data for measurement height $\mathrm{MH} 2$

\begin{tabular}{|c|c|c|c|c|c|c|c|c|}
\hline \multirow[t]{2}{*}{ Groups } & \multirow[t]{2}{*}{ Variable } & \multicolumn{4}{|l|}{ Mean \pm SEM } & \multicolumn{3}{|l|}{$p$ value } \\
\hline & & $C S$ & $\mathrm{~cd}$ & Is & $\mathrm{ms}$ & Cs vs. Is & CS vs. ms & Is vs. ms \\
\hline \multirow[t]{2}{*}{ All } & $\mathrm{SO} 2$ & $36.0 \pm 2.0$ & $70.1 \pm 1.4$ & $36.0 \pm 2.0$ & $41.0 \pm 1.9$ & 0.741 & 0.232 & 0.176 \\
\hline & Flow & $12.4 \pm 1.7$ & $84.4 \pm 4.6$ & $20.2 \pm 1.4$ & $17.7 \pm 1.1$ & $<0.001$ & $<0.001$ & 0.259 \\
\hline \multirow[t]{2}{*}{ Men } & $\mathrm{SO} 2$ & $36.3 \pm 2.8$ & $74.0 \pm 1.4$ & $37.5 \pm 2.5$ & $43.1 \pm 2.4$ & 0.880 & 0.384 & 0.268 \\
\hline & Flow & $13.5 \pm 2.6$ & $89.9 \pm 6.2$ & $21.5 \pm 2.0$ & $20.5 \pm 1.6$ & $<0.001$ & $<0.001$ & 0.769 \\
\hline \multirow[t]{2}{*}{ Women } & $\mathrm{SO} 2$ & $35.5 \pm 3.0$ & $64.6 \pm 2.6$ & $33.8 \pm 3.2$ & $38.1 \pm 3.0$ & 0.697 & 0.253 & 0.329 \\
\hline & Flow & $10.89 \pm 1.8$ & $76.5 \pm 6.6$ & $18.0 \pm 1.6$ & $13.7 \pm 1.4$ & $<0.001$ & 0.180 & 0.082 \\
\hline \multirow[t]{2}{*}{ Nonsmokers } & $\mathrm{SO} 2$ & $36.3 \pm 2.4$ & $69.5 \pm 1.7$ & $35.8 \pm 2.2$ & $41.2 \pm 2.0$ & 0.914 & 0.320 & 0.292 \\
\hline & Flow & $12.9 \pm 2.0$ & $86.3 \pm 5.5$ & $20.4 \pm 1.6$ & $18.6 \pm 1.3$ & $<0.001$ & $<0.001$ & 0.538 \\
\hline \multirow[t]{2}{*}{ Smokers } & $\mathrm{SO} 2$ & $34.8 \pm 4.0$ & $72.2 \pm 2.4$ & $37.0 \pm 4.7$ & $40.4 \pm 5.1$ & 0.526 & 0.466 & 0.366 \\
\hline & Flow & $10.7 \pm 2.8$ & $77.4 \pm 7.7$ & $19.3 \pm 2.7$ & $14.2 \pm 2.0$ & 0.012 & 0.344 & 0.258 \\
\hline
\end{tabular}

$\mathrm{SO} 2$ in \%, Flow in $\mathrm{AU}$

cs central superficial (2 mm deep), $c d$ central in-depth (8 $\mathrm{mm}$ deep), Is lateral superficial (2 $\mathrm{mm}$ deep), $\mathrm{ms}$ superficial (2 mm deep), SEM standard error of the mean

provides advantages for removing Haglund exostoses because of the position of the calcaneus in relation to the Achilles tendon. Little et al. reported good results with low complication rates for treating distal tibial and talar fractures using this lateral approach [7]. An anatomical study evaluating the lateral approach for hindfoot arthrodesis demonstrated a risk for injuries of the venous system [6]. In addition, the lateral malleolar branches of the peroneal artery were often endangered while the sural nerve remained intact in all specimens that were evaluated in this study [6].

In the present study, the lowest microperfusion was observed centrally (superficially) on the Achilles tendon. This finding is consistent with previous studies of lower limb angiosomes [30]. Taylor and Pan [30] showed that the two angiosomes of the peroneal vessels and the vessels from the posterior tibial artery meet on the lower leg in the midline above the Achilles tendon. In a clinical

Table 4 Comparison between $\mathrm{MH} 1$ and $\mathrm{MH} 2$ for $\mathrm{SO} 2$ and Flow in the Achilles tendon

\begin{tabular}{lll}
\hline Groups & Variable & $p$ value \\
\hline Total & SO2 & $<0.001$ \\
& Flow & 0.048 \\
Men & SO2 & $<0.001$ \\
& Flow & 0.056 \\
Women & SO2 & $<0.001$ \\
& Flow & 0.356 \\
Nonsmokers & SO2 & $<0.001$ \\
& Flow & 0.054 \\
Smokers & SO2 & 0.001 \\
& Flow & 0.568 \\
\hline
\end{tabular}

study, Hammit et al. [14] reported that an approach direct over the Achilles tendon yielded good results and low complication rates. However, the authors rated the development of a painful or unsightly scar as critical, although no such a complication occurred in their study [14]. They speculated that their good results were due to the access in the watershed area between the two angiosomes [14].

The medial approach, supplied by the posterior tibial artery, exhibited significantly better microcirculation than the central approach in the present study except of the $\mathrm{SO} 2$ for the distal measurement point, but was somewhat inferior to that of the lateral area (MH1 Flow). The medial approach is widely used to treat Haglund exostoses and Achilles tendon ruptures, because here the sural nerve cannot be damaged and the scar is not as problematic as on the tendon $[3,5,15]$.

The measurements superficially and deep in the tendon showed significantly worse microperfusion at $\mathrm{MH} 1$ among all subjects. This corresponds with the experience that ruptures and degenerations typically occur at this level and contradicts the anatomical study of Schmidt-Rohlfing et al. [17] who could not see any differences in the middle part of the tendon. However, our results confirmed the anatomical study of Chan et al. [18], who did a histological and angiographic study and concluded that the middle Achilles tendon is hypovascular [18].

Higher BMI is considered a risk factor for Achilles tendon degeneration [16]. Thus, it was expected that perfusion would also correlate negatively with BMI. A negative correlation between perfusion in the tendon and BMI was not seen in this study. On the contrary, within all subjects, BMI correlated significantly and positively with lateral $\mathrm{SO} 2$ at $\mathrm{MH} 1$ and with medial Flow at MH2. However, BMI negatively correlated with superficial 
perfusion of the tendon, however, only for smokers and women.

A negative correlation between age and tendinous blood flow was detected for men, which is consistent with previous observations that female gender is a protective factor for Achilles tendon rupture [31] and may also allude the high incidence of Achilles tendon rupture for men in the fourth and fifth decades of their life [32]. These findings may be caused by an increased vascular stiffness, decreased vascular density, or impaired vascular organization, which can lead to a decreased blood supply in aging skin [33]. For that reason, the results of operative treatment of geriatric foot and ankle fractures are essentially determined by the soft tissue management [12] and minimally invasive techniques are recommended in elderly patients [34]. There was also an improved perfusion in nonsmokers compared to smokers seen for $\mathrm{SO} 2$ lateral at $\mathrm{MH}$ 1 and for Flow medial at MH 2. In a large meta-analysis of 140 studies and 479,150 patients across all surgical specialties, smokers were found to have a higher incidence of postoperative healing complications compared to nonsmokers [35]. In contrast to this, a meta-analysis in trauma surgery, and treatment of closed calcaneal fracture specifically, involving 1559 patients with 1651 fractures, smoking was not found to have a significant influence on posttraumatic and postoperative wound complications [36].

In line with the study of Gardner et al. [37], our data showed a gender difference in microcirculatory parameters in favor of males. This could be caused by gender-specific physiological differences, such as the ratio of skeletal muscle and thickness of subcutaneous fat [38]. Thicker muscle, less subcutaneous fat, and higher blood vessel density in men could lead to this difference in microcirculation, even in rest. However, we cannot estimate microcirculation in a trauma situation, which can be different. Further studies are necessary to clarify the question of gender-specific influence on microcirculatory parameters, since some studies could not show any dependence from gender [23].

A study by Bruggeman et al. [39] examined 164 patients with Achilles tendon repair. More than 10\% of the patients experienced wound healing problems [39]. Among others, smoking and female gender were identified as risk factors, whereas BMI and age did not play a considerable role [39]. In the current study, we confirmed the negative influence of smoking. Women also exhibited reduced perfusion compared to men. We found both negative and positive correlations between BMI and superficial dermal perfusion. Thus, the results are consistent with those of Bruggeman et al. [39].

This examination was carried out exclusively on healthy and uninjured subjects. Conclusions on patients suffering from a degenerative hindfoot disease or hindfoot injury are therefore limited. Although the study confirms the presumed superficial "underperfusion" of the tendon in the centered area, a change in perfusion as the sole cause of Achilles tendon degeneration is not substantiated by limited data. Based on this work, the lateral approach may be recommended but the extent to which microcirculation is affected by the surgical approach itself cannot be answered. Dragu et al. [40] showed significant changes in the microperfusion parameters of the evaluated areas after abdominoplasty. These authors showed that previously well-oxygenated parts of the approach underwent a significant decrease in oxygen saturation upon mobilization and suturing, while other parts of the wound edges showed an increase of microperfusion [40].

Thus, it is possible that a cut next to the watershed area above the Achilles tendon may lead to a reduced blood flow from this direction (for the medial approach from lateral and vice versa) as there are likely very few collaterals in this area and that mobilization of the tissue from the medial or lateral side may further affect microperfusion. This consideration may support a central access route to the Achilles tendon as this area is supplied from both the posterior tibial artery and the peroneal artery as it is suspected by Hammit et al. [14]. The disadvantage of this approach is that it may lead to a painful or unsightly scar.

Based on the determination of the microcirculation in healthy subjects, a final assessment of the different approaches is not possible, and further studies are necessary applying laser Doppler/white light spectroscopy in investigating the perfusion of the different surgical approaches to the hindfoot during and after surgery.

\section{Conclusion}

Dermal microcirculation is significantly limited above the Achilles tendon. Microcirculation is better lateral and medial than central on the tendon. It is also better on the proximal lateral side than proximal medial. Furthermore, differences in microperfusion vary between men and women with a superiority for men having higher values. The negative effect of smoking on microcirculation was partially confirmed. The Achilles tendon shows a significantly reduced microperfusion $5 \mathrm{~cm}$ proximal to the calcaneal tubercle. The influence of these results on everyday clinical practice requires further clarification in additional investigations, including clinical studies.

\section{Abbreviations}

BMI: Body mass index; Flow: Blood flow (arbitrary unit); MH: Measuring height; NS: Nonsmokers; O2C: Oxygen to see, laser Doppler/white light spectroscopy; S: Smokers; SO2: Capillary venous oxygen saturation (percent)

Availability of data and materials

The datasets analyzed during the current study are available from the corresponding author on reasonable request. 


\section{Declarations}

All procedures performed in studies involving human participants were in accordance with the ethical standards of the institutional and/or national research committee and with the 1964 Helsinki Declaration and its later amendments or comparable ethical standards.

\section{Authors' contributions}

KK and MK had full access to all of the data in the study and take responsibility for the integrity of the data and the accuracy of the data analysis. All authors meet all three of the requirements for authorship. BG, $\mathrm{JBC}, \mathrm{AM}, \mathrm{SN}$, and BSK were highly involved in the planning and execution of this study. Furthermore, KK, KH, CDW, BG, AM, BSK, and SN were highly involved in the acquisition of data and in the process of data interpretation. $\mathrm{JBC}, \mathrm{KH}$, and CDW made a significant contribution to the analysis and interpretation of data. Furthermore, they took part in the manuscript review process and revised it critically. In this way, they provided an important intellectual content in line with study execution. MK acted as the initiator of the study and was highly involved in the advancement of the conception. All authors read and approved the final manuscript.

\section{Authors' information}

KK (M.D., Associate Prof.) Department of Foot and Ankle Surgery, Catholic Hospital Mainz, Germany

BG (Prof.) AO Research Institute Davos, Davos, Switzerland

JBC (M.D.) Department of Orthopaedic Trauma, University of Aachen Medical Center, Germany

AM (M.D., Associate Prof.) Department of Oral and Maxillofacial Surgery, University of Aachen Medical Center, Germany

SN (M.D., Associate Prof.) Department of Radiology, University of Aachen Medical Center, Germany

BSK (M.D., Associate Prof.) Department of Plastic Surgery, Reconstructive and Hand Surgery, University of Aachen Medical Center, Germany

KH (M.D., MHBA) Department of Orthopaedic Trauma, University of Aachen Medical Center, Germany

CDW (M.D.) Department of Orthopaedic Trauma, University of Aachen Medical Center, Germany

MK (M.D., Associate Prof., MME, MHBA) Department of Orthopaedic Trauma, University of Aachen Medical Center, Germany

\section{Ethics approval and consent to participate}

Institutional Review Board approval was granted before initiation of this study, and strict confidentiality guidelines were followed (Local Ethics Committee Reference Number EK 346/14). Participants provided informed consent for the use of their results in this study and for publication at the time of enrollment.

Ethics committee of the RWTH Aachen University Hospital, ethics approval EK 346/14.

\section{Consent for publication}

Consent for publication, including photographic images, was provided by the participants at the time of enrollment.

\section{Competing interests}

The authors declare that they have no competing interests.

\section{Publisher's Note}

Springer Nature remains neutral with regard to jurisdictional claims in published maps and institutional affiliations.

\section{Author details}

'Department of Foot and Ankle Surgery, Catholic Hospital Mainz, Mainz, Germany. ${ }^{2} \mathrm{AO}$ Research Institute Davos, Davos, Switzerland. ${ }^{3}$ Department of Orthopaedic Trauma, University of Aachen Medical Center, Aachen, Germany. ${ }^{4}$ Department of Oral and Maxillofacial Surgery, University of Aachen Medical Center, Aachen, Germany. ${ }^{5}$ Department of Radiology, University of Aachen Medical Center, Aachen, Germany. ${ }^{6}$ Department of Plastic Surgery, Reconstructive and Hand Surgery, University of Aachen Medical Center, Aachen, Germany.
Received: 2 March 2018 Accepted: 29 May 2018

Published online: 07 June 2018

\section{References}

1. Knobe M, Gradl G, Klos K, Corsten J, Dienstknecht T, Rath B, Sonmez TT, Hoeckle $C$, Pape $H C$. Is percutaneous suturing superior to open fibrin gluing in acute Achilles tendon rupture? Int Orthop. 2014; https://doi.org/10.1007/ s00264-014-2615-4.

2. Paavola M, Orava S, Leppilahti J, Kannus P, Jarvinen M. Chronic Achilles tendon overuse injury: complications after surgical treatment. An analysis of 432 consecutive patients. Am J Sports Med. 2000;28(1):77-82.

3. Cretnik A, Frank A. Incidence and outcome of rupture of the Achilles tendon. Wien Klin Wochenschr. 2004;116(Suppl 2):33-8.

4. Cretnik A, Kosir R, Kosanovic M. Incidence and outcome of operatively treated Achilles tendon rupture in the elderly. Foot Ankle Int. 2010;31 (1):14-8. https:// doi.org/10.3113/FAl.2010.0014.

5. Amlang MH, Maffuli N, Longo UG, Stubig T, Imrecke J, Hufner T. Surgica treatment of Achilles tendon rupture. Unfallchirurg. 2010;113(9):712-20. https://doi.org/10.1007/s00113-010-1809-5.

6. Rausch S, Loracher C, Frober R, Gueorguiev B, Wagner A, Gras F, Simons P, Klos K. Anatomical evaluation of different approaches for tibiotalocalcaneal arthrodesis. Foot Ankle Int. 2013; https://doi.org/10.1177/1071100713517095.

7. Little MT, Berkes MB, Lazaro LE, Sculco PK, Helfet DL, Lorich DG. Complications following treatment of supination external rotation ankle fractures through the posterolateral approach. Foot Ankle Int. 2013;34(4): 523-9. https://doi.org/10.1177/1071100713477626.

8. Fuhrmann RA, Pillukat T. Subtalar arthrodesis. Oper Orthop Traumatol. 2016; 28(3):177-92. https://doi.org/10.1007/s00064-016-0438-8.

9. Raikin SM, Winters BS, Daniel JN. The RAM classification: a novel, systematic approach to the adult-acquired flatfoot. Foot Ankle Clin. 2012;17(2):169-81. https://doi.org/10.1016/j.fcl.2012.03.002

10. Lowery NJ, Woods JB, Armstrong DG, Wukich DK. Surgical management of Charcot neuroarthropathy of the foot and ankle: a systematic review. Foot Ankle Int. 2012;33(2):113-21. https://doi.org/10.3113/FAl.2012.0113.

11. Putz C, Mertens EM, Wolf SI, Geisbusch A, Niklasch M, Gantz S, Doderlein L, Dreher T, Klotz MC. Equinus correction during multilevel surgery in adults with cerebral palsy. Foot Ankle Int. 2018; https://doi.org/10.1177/ 1071100718765161.

12. Klos $K$, Simons $P$, Mückley $T$, Karich $B$, Randt $T$, Knobe M. Fractures of the ankle joint in elderly patients. Unfallchirurg. 2017;120(11):979-92.

13. Ettinger S, Razzaq R, Waizy H, Claassen L, Daniilidis K, Stukenborg-Colsman C, Plaass C. Operative treatment of the insertional Achilles tendinopathy through a transtendinous approach. Foot Ankle Int. 2016;37(3):288-93. https://doi.org/10.1177/1071100715609921.

14. Hammit MD, Hobgood ER, Tarquinio TA. Midline posterior approach to the ankle and hindfoot. Foot Ankle Int. 2006;27(9):711-5.

15. Schepsis AA, Leach RE. Surgical management of Achilles tendinitis. Am J Sports Med. 1987;15(4):308-15.

16. Holmes $\mathrm{GB}$, Lin J. Etiologic factors associated with symptomatic Achilles tendinopathy. Foot Ankle Int. 2006;27(11):952-9. https://doi.org/10.1177/ 107110070602701115

17. Schmidt-Rohlfing B, Graf J, Schneider U, Niethard FU. The blood supply of the Achilles tendon. Int Orthop. 1992;16(1):29-31.

18. Chen TM, Rozen WM, Pan WR, Ashton MW, Richardson MD, Taylor GI. The arterial anatomy of the Achilles tendon: anatomical study and clinical implications. Clin Anat. 2009:22(3):377-85. https://doi.org/10.1002/ca.20758.

19. Beckert $\mathrm{S}$, Witte MB, Konigsrainer A, Coerper $\mathrm{S}$. The impact of the MicroLightguide $\mathrm{O} 2 \mathrm{C}$ for the quantification of tissue ischemia in diabetic foot ulcers. Diabetes Care. 2004;27(12):2863-7.

20. Knobloch K, Grasemann R, Spies M, Vogt PM. Intermittent KoldBlue cryotherapy of $3 \times 10$ min changes mid-portion Achilles tendon microcirculation. Br J Sports Med. 2007;41(6):e4. https://doi.org/10.1136/ bjsm.2006.030957.

21. Kubli S, Waeber B, Dalle-Ave A, Feihl F. Reproducibility of laser Doppler imaging of skin blood flow as a tool to assess endothelial function. J Cardiovasc Pharmacol. 2000;36(5):640-8.

22. Ladurner R, Feilitzsch M, Steurer W, Coerper S, Konigsrainer A, Beckert S. The impact of a micro-lightguide spectrophotometer on the intraoperative assessment of hepatic microcirculation: a pilot study. Microvasc Res. 2009; 77(3):387-8. https://doi.org/10.1016/j.mvr.2009.01.008. 
23. Kösters AK, Ganse B, Gueorguiev B, Klos K, Modabber A, Nebelung S, Kim BS, Knobe M. Effects of low-intensity pulsed ultrasound on soft tissue micro-circulation in the foot. Int Orthop. 2017;41(10):2067-74. https://doi. org/10.1007/s00264-017-3574-3.

24. Ganse B, Pishnamaz M, Kobbe P, Herren C, Gradl-Dietsch G, Bohle F, Johannes B, Kim BS, Horst K, Knobe M. Microcirculation in open vs. minimally invasive dorsal stabilization of thoracolumbar fractures. PLoS One. 2017;12(11):e0188115. https://doi.org/10.1371/journal.pone.0188115.

25. Forst T, Hohberg C, Tarakci E, Forst S, Kann P, Pfutzner A. Reliability of lightguide spectrophotometry $(\mathrm{O} 2 \mathrm{C})$ for the investigation of skin tissue microvascular blood flow and tissue oxygen supply in diabetic and nondiabetic subjects. J Diabetes Sci Technol. 2008;2(6):1151-6.

26. Jorgensen LP, Schroeder TV. Micro-lightguide spectrophotometry for tissue perfusion in ischemic limbs. J Vasc Surg. 2012;56(3):746-52. https://doi.org/ 10.1016/j.jvs.2012.02.068

27. Cho JK, Moon DJ, Kim SG, Lee HG, Chung SP, Yoon CJ. Relationship between healing time and mean perfusion units of laser Doppler imaging (LDI) in pediatric burns. Burns. 2009;35(6):818-23. https://doi.org/10.1016/j. burns.2008.12.009.

28. Merz KM, Pfau M, Blumenstock G, Tenenhaus M, Schaller HE, Rennekampff HO. Cutaneous microcirculatory assessment of the burn wound is associated with depth of injury and predicts healing time. Burns. 2010;36(4): 477-82. https://doi.org/10.1016/j.burns.2009.06.195.

29. Webb J, Moorjani N, Radford M. Anatomy of the sural nerve and its relation to the Achilles tendon. Foot Ankle Int. 2000;21 (6):475-7.

30. Taylor Gl, Pan WR. Angiosomes of the leg: anatomic study and clinical implications. Plast Reconstr Surg. 1998;102(3):599-616. discussion 617-598

31. Vosseller JT, Ellis SJ, Levine DS, Kennedy JG, Elliott AJ, Deland JT, Roberts MM, O'Malley MJ. Achilles tendon rupture in women. Foot Ankle Int. 2013; 34(1):49-53. https://doi.org/10.1177/1071100712460223.

32. Hess GW. Achilles tendon rupture: a review of etiology, population, anatomy, risk factors, and injury prevention. Foot Ankle Spec. 2010;3(1):2932. https://doi.org/10.1177/1938640009355191.

33. Bentov I, Reed MJ. The effect of aging on the cutaneous microvasculature. Microvasc Res. 2015;100:25-31. https://doi.org/10.1016/..mvr.2015.04.004.

34. Karich B, Klos K, Simons $P$, et al. Minimally invasive osteosynthesis after ankle fractures in geriatric patients: surgical technique with the aid of headless full thread screws. Unfallchirurg. 2017; https://doi.org/10.1007/s00113-017-04222. [Epub ahead of print]

35. Sørensen LT. Wound healing and infection in surgery: the clinical impact of smoking and smoking cessation: a systematic review and meta-analysis. Arch Surg. 2012;147(4):373-83. https://doi.org/10.1001/archsurg.2012.5.

36. Zhang W, Chen E, Xue D, et al. Risk factors for wound complications of closed calcaneal fractures after surgery: a systematic review and metaanalysis. Scand J Trauma Resusc Emerg Med. 2015;23(1):18. https://doi.org/ 10.1186/s13049-015-0092-4

37. Gardner AW, Montgomery PS, Blevins SM, et al. Gender and ethnic differences in arterial compliance in patients with intermittent claudication. J Vasc Surg. 2010;51(3):610-5. https://doi.org/10.1016/j.jvs.2009.09.059.

38. Kao WL, Sun CW. Gender-related effect in oxygenation dynamics by using far-infrared intervention with near-infrared spectroscopy measurement: a gender differences controlled trial. PLoS One. 2015;10(11):e0135166. https:// doi.org/10.1371/journal.pone.0135166.

39. Bruggeman NB, Turner NS, Dahm DL, Voll AE, Hoskin TL, Jacofsky DJ, Haidukewych GJ. Wound complications after open Achilles tendon repair: an analysis of risk factors. Clin Orthop Relat Res. 2004;427:63-6.

40. Dragu A, Schnurer S, Horbach T, Unglaub F, Arkudas A, Beier JP, Kneser U, Horch RE. Evaluation of intra-operative abdominal wall perfusion in post-bariatric abdominal dermolipectomy. Obes Facts. 2012;5(5):651-9. https:/doi.org/10.1159/000343662.

Ready to submit your research? Choose BMC and benefit from:

- fast, convenient online submission

- thorough peer review by experienced researchers in your field

- rapid publication on acceptance

- support for research data, including large and complex data types

- gold Open Access which fosters wider collaboration and increased citations

- maximum visibility for your research: over $100 \mathrm{M}$ website views per year

At BMC, research is always in progress.

Learn more biomedcentral.com/submissions 